\title{
Cardiac Autonomic Dysfunction in Patients with Diabetic Retinopathy
}

\author{
S. E. Smith, S. A. Smith and P. M. Brown \\ Departments of Pharmacology and Medicine, St. Thomas's Hospital Medical School, London, UK
}

\begin{abstract}
Summary. Cardiac autonomic function was assessed by an on-line microcomputer technique in 67 patients with diabetic retinopathy. Sixteen patients had a resting tachycardia ( 92 beats/min or greater). R-R interval variations were abnormally low in 29 patients at rest, in 35 during deep breathing and in four in response to a Valsalva manoeuvre. The severity of retinopathy correlated significantly with the degree of autonomic dysfunction assessed by the interval variations at rest $(p<0.05)$, during deep breathing ( $p$ $<0.01)$, and with the Valsalva manoeuvre $(p<0.01)$. The results emphasise the important association between diabetic retinopathy and cardiac autonomic dysfunction.
\end{abstract}

Key words: Diabetic neuropathy, diabetic retinopathy, R-R intervals, sinus arrhythmia, glycosylated haemoglobin.

The diabetic complications of retinopathy, neuropathy and nephropathy frequently coexist as shown in the comprehensive study by Pirart [1]. Whether this association extends to the autonomic nervous system can now be assessed with recently developed techniques for studying autonomic function $[2,3]$. A computer-based technique for measuring and analysing cardiac beat-to-beat intervals [4] was used in the present study of 67 patients attending a diabetic retinopathy clinic. The aim was to measure the prevalence of cardiac autonomic dysfunction in diabetic patients with retinopathy and to determine whether the degree of dysfunction correlated with the severity of retinopathy.

\section{Methods}

Sixty-seven consecutive patients of both sexes (mean age 48.6 years, range $21-70$ years) attending a diabetic retinopathy clinic participated. The mean duration of diabetes was 17.3 years (range
1-41 years) and patients treated with either insulin or oral hypoglycaemic agents were included. The mean age of the 47 insulin treated patients was 44.1 years and their mean duration of disease was 20.7 years. The 20 orally treated patients were older (mean age 59.0 years) and had a shorter known duration of disease (mean 9.3 years). Patients taking drugs likely to interfere with the cardiovascular system were excluded from the study.

Patients were examined lying down in a quiet room while waiting to see the ophthalmologist and before instillation of mydriatic eyedrops. R-R intervals were measured from an electrocardiogram, converted to digital form by an analog-digital converter, then fed into a computer for immediate analysis. All the apparatus, including the computer (a Commodore Pet Series 2001 microcomputer) fitted a standard medical trolley that could be taken to the bedside for an assessment of cardiac autonomic function [4].

The mean and standard deviation of 255 successive R-R intervals (excluding abnormal intervals due to extrasystoles) were measured with the subject at rest. The patient was then instructed to breathe deeply five times at a rate of 6 breaths $/ \mathrm{min}$ and the mean difference between the shortest (inspiration) and the longest R-R interval (expiration) was calculated. Lastly, a Valsalva manoeuvre $(40 \mathrm{mmHg}$ for $10 \mathrm{~s}$ ) was performed and the ratio of the longest : shortest R-R intervals was calculated [5]. The deep breathing difference was not obtained in one patient in whom the respiratory effort was unsatisfactory. Two patients were unable to perform the Valsalva manoeuvre satisfactorily.

Cardiac autonomic dysfunction was identified by comparing the results with those from a group of 174 healthy subjects (mean age 48.6 years: range $16-89$ years) [4]. The results from that study showed that the mean resting R-R interval was independent of sex and age, and the normal range (mean $\pm 2 \mathrm{SD}$ ) was $655-1141 \mathrm{~ms}$ (equivalent to resting heart rates of 53-92 beats/min). Normal ranges for the three measures of R-R variation (standard deviation, deep breathing difference and Valsalva ratio) were all found to be dependent on age. Additionally, the standard deviation and deep breathing difference were strongly dependent on the size of the mean R-R interval. Regression equations were obtained which described these relationships and these were stored in the computer program, namely:

$\ln \mathrm{y}_{\mathrm{I}}=2.793-0.0146 \mathrm{x}_{1}+0.0019 \mathrm{x}_{2}$

$\ln \mathrm{y}_{2}=4.764-0.0192 \mathrm{x}_{1}+0.0017 \mathrm{x}_{2}$

$\mathrm{y}_{3}=2.156-0.0091 \mathrm{x}_{1}$

where $\mathrm{x}_{1}=$ age in years, $\mathrm{x}_{2}=$ mean R-R interval length in $\mathrm{ms}, \mathrm{y}_{1}=$ standard deviation in $\mathrm{ms}, \mathrm{y}_{2}=$ deep breathing difference in $\mathrm{ms}, \mathrm{y}_{3}$ $=$ Valsalva ratio. The lower limit of the normal range, which thus differed according to the individual's age and resting heart rate, was defined as the 2.5 percentile and calculated from the variance of the regression by standard statistical methods [6].

Due to these factors that normally affect the size of the R-R interval variations, the occurrence of a low result in the standard devi- 
ation test, for example, could indicate either autonomic dysfunction, old age or a fast heart rate. The above equations can be used to predict an expected value according to the individual's age and heart rate. For example, with a mean interval of $600 \mathrm{~ms}$ (or $100 \mathrm{beats} / \mathrm{min}$ ) a 20 year old will have an expected standard deviation of $37 \mathrm{~ms}$ but in a 60 year old it will be $21 \mathrm{~ms}$. Similarly, at age 40 years the standard deviation will be $28 \mathrm{~ms}$ at a mean interval of $600 \mathrm{~ms}$ or $59 \mathrm{~ms}$ at a mean interval of $1000 \mathrm{~ms}$ (or 60 beats $/ \mathrm{min}$ ). Thus for each retinopathy patient, his observed result was expressed as a percentage of that predicted from the equations to ob-

Table 1. Retinopathy classification

\begin{tabular}{llll}
\hline Grade & Definition & No. of patients \\
\hline 1 & $\begin{array}{l}\text { The occasional } \\
\text { microaneurysm in the } \\
\text { peripheral retina }\end{array}$ & 4 & $\begin{array}{l}\text { mild } \\
\text { retinopathy }\end{array}$ \\
2 & $\begin{array}{l}\text { Microaneurysms, } \\
\text { exudates or cotton wool } \\
\text { spots in the peripheral } \\
\text { retina }\end{array}$ & 18 & \\
\hline 3 & $\begin{array}{l}\text { New vessels on the } \\
\text { peripheral retina } \\
\text { New vessels on the optic } \\
\text { disc or retinitis } \\
\text { proliferans anywhere on } \\
\text { the retina }\end{array}$ & 6 & severe \\
retinopathy & & \\
& $\begin{array}{l}\text { Advanced diabetic eye } \\
\text { disease with gross } \\
\text { vitreous haemorrhage or } \\
\text { secondary glaucoma }\end{array}$ & 12 & \\
\hline
\end{tabular}

tain a meaningful indicator of autonomic dysfunction for the correlation analysis. The Valsalva ratio was expressed similarly according to the formula:

$\frac{\text { observed ratio }-1}{\text { predicted ratio }-1} \times 100 \%$

All patients had evidence of retinopathy on fundoscopic examination, the severity of which was classified on a scale of 1-5 (Table 1) similar to that described by Donovan [7]. The worse eye was assessed in cases where the retinae differed. Eyes previously treated with photocoagulation could not be graded as the retinal picture was changed, in which case the other eye was assessed if possible. For this reason, the severity of retinopathy was classified in only 58 patients.

Blood biochemistry included measurement of creatinine (in 50 patients) and the percentage of glycosylated haemoglobin $\left(\mathrm{HbA}_{1} \%\right)$ by a microcolumn method [8] (in 51 patients). The normal ranges for plasma creatinine are $53-106 \mu \mathrm{mol} / \mathrm{I}$ in males and $44-88 \mu \mathrm{mol} / 1$ in females. The normal range for $\mathrm{HbA}_{1}$ is $6.0 \%-8.5 \%$ [8].

Pearson correlation coefficients were calculated to test for associations between the autonomic measures, the retinopathy grade, the duration of diabetes and the blood biochemistry results. The distribution of patients within the retinopathy classification is not strictly normal (Table 1) so that the probability values assigned to these coefficients in Table 2 should be considered as estimates only.

\section{Results}

Cardiac autonomic dysfunction occurred commonly in the retinopathy patients. Sixteen out of 67 had a mean R-R interval below the normal range, indicating

Table 2. Correlation matrix relating the severity of retinopathy to cardiac autonomic dysfunction, known duration of disease, plasma creatinine and $\mathrm{HbA}_{1}$ in diabetic patients

\begin{tabular}{|c|c|c|c|c|c|c|c|c|}
\hline & $\begin{array}{l}\text { Retinopathy } \\
\text { classification }\end{array}$ & $\begin{array}{l}\text { Mean R-R } \\
\text { interval (ms) }\end{array}$ & $\begin{array}{l}\text { Standard } \\
\text { deviation } \\
\text { (\% of ex- } \\
\text { pected) }\end{array}$ & $\begin{array}{l}\text { Deep } \\
\text { breathing } \\
\text { difference }(\% \\
\text { of expected })\end{array}$ & $\begin{array}{l}\text { Valsalva ratio } \\
\text { ( } \% \text { of ex- } \\
\text { pected) }\end{array}$ & $\begin{array}{l}\text { Known } \\
\text { duration of } \\
\text { diabetes } \\
\text { (years) }\end{array}$ & $\begin{array}{l}\text { Plasma } \\
\text { creatinine } \\
(\mu \mathrm{mol} / 1)\end{array}$ & $\begin{array}{l}\mathrm{HbA}_{1} \\
(\%)\end{array}$ \\
\hline $\begin{array}{l}\text { Retinopathy } \\
\text { classification }\end{array}$ & 1.0 & & & & & & & \\
\hline $\begin{array}{l}\text { Mean R-R interval } \\
\text { (ms) }\end{array}$ & -0.13 & 1.0 & & & & & & \\
\hline $\begin{array}{l}\text { Standard deviation } \\
\text { (\% of expected) }\end{array}$ & $-0.33^{\mathrm{a}}$ & $0.29^{a}$ & 1.0 & & & & & \\
\hline $\begin{array}{l}\text { Deep breathing } \\
\text { difference (\% of } \\
\text { expected) }\end{array}$ & $-0.40^{b}$ & 0.21 & $0.67^{\mathrm{c}}$ & 1.0 & & & & \\
\hline $\begin{array}{l}\text { Valsalva ratio } \\
\text { (\% of expected) }\end{array}$ & $-0.36^{b}$ & 0.21 & $0.48^{\mathrm{c}}$ & $0.57^{\mathrm{c}}$ & 1.0 & & & \\
\hline $\begin{array}{l}\text { Known duration of } \\
\text { diabetes (years) }\end{array}$ & $0.30^{\mathrm{a}}$ & -0.14 & 0.08 & -0.04 & -0.10 & 1.0 & & \\
\hline $\begin{array}{l}\text { Plasma creatinine } \\
(\mu \mathrm{mol} / \mathrm{l})\end{array}$ & $0.30^{\mathrm{a}}$ & 0.11 & -0.03 & -0.08 & -0.10 & -0.14 & 1.0 & \\
\hline $\mathrm{HbA}_{1}(\%)$ & 0.17 & -0.20 & -0.18 & -0.21 & -0.04 & $0.31^{\mathrm{a}}$ & -0.22 & 1.0 \\
\hline
\end{tabular}

${ }^{\mathrm{a}} p<0.05 ;{ }^{\mathrm{b}} p<0.01 ;{ }^{\mathrm{c}} p<0.001$ 


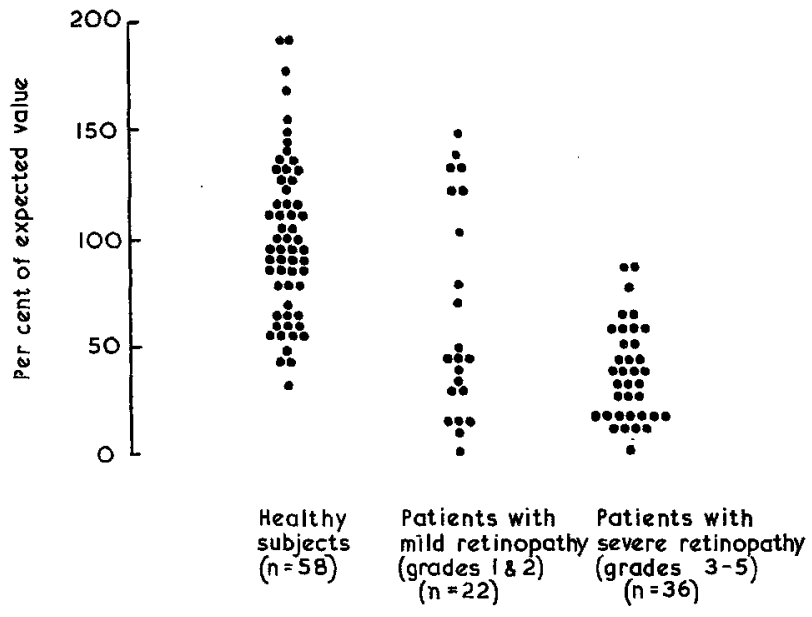

Fig. 1. R-R interval variation on deep breathing in 58 patients with diabetic retinopathy and 58 age- and sex-matched healthy subjects. Results are expressed as percentages of values predicted for each individual's age and mean R-R interval. Normal subjects show a wide inter-individual variability in response to this test as shown by the spread of values about $100 \%$. Despite this, the retinopathy patients clearly have reduced deep breathing responses related to the severity of retinal disease. (The normal data formed part of a study of healthy subjects described elsewhere [4])

a resting tachycardia of 92 beats/min or greater. From the measurements of $\mathrm{R}-\mathrm{R}$ interval variation, 29 patients were found to have an abnormally low standard deviation, 35 an abnormally reduced deep breathing difference and four patients had a Valsalva ratio below the normal range.

The plasma creatinine was $93.6 \pm 32.1 \mu \mathrm{mol} / \mathrm{l}$ (mean \pm SD) and the level was above the normal range in $12 / 50$ patients. The $\mathrm{HbA}_{1}$ was $11.6 \% \pm 2.3 \%$ (mean \pm SD), most patients $(46 / 51)$ having levels above the normal range.

The severity of retinopathy correlated significantly with the degree of cardiac autonomic dysfunction as assessed by the standard deviation $(p<0.05)$, deep breathing difference $(p<0.01)$ and Valsalva ratio $(p$ $<0.01$ ) tests (Table 2). This is illustrated in Figure 1 which shows the reduced deep breathing difference in patients with mild (grades 1 and 2) and severe (3-5) retinopathy compared with the results for a group of age- and sex-matched healthy subjects. There was no relationship between the severity of retinopathy and the mean R-R interval length. The degree of retinal disease was significantly related to the known duration of diabetes $(p<0.05)$ and the plasma creatinine level $(p<0.05)$ but not to the percentage of $\mathrm{HbA}_{1}$.

Reductions in the three $R-R$ interval variation measures correlated closely as shown by the coefficients in Table 2. This correlation did not extend, however, to the length of the mean R-R interval, except for a weak correlation $(p<0.05)$ with reduced standard deviation values. None of the cardiac autonomic measures was related to the known duration of disease, plasma creatinine or $\mathrm{HbA}_{1}$ level.

\section{Discussion}

The frequency with which abnormalities of cardiac autonomic function were found in these retinopathy patients indicates that the association between retinopathy and neuropathy involves autonomic as well as somatic nerves. Further, the correlation between the severity of retinopathy and the degree of cardiac autonomic dysfunction suggests a coincident natural history. This suggestion accords with the findings of Pirart [1] who showed in a study of over 4,000 diabetic patients followed up for 25 years that retinopathy, somatic neuropathy and nephropathy developed in direct relationship with the degree and duration of chronic hyperglycaemia.

Neither autonomic dysfunction nor the severity of retinopathy correlated significantly with the level of $\mathrm{HbA}_{1}$. It is known that the $\mathrm{HbA}_{1}$ level is an unreliable indicator of hyperglycaemia in patients with nephropathy [9] but exclusion of the values from the 12 patients in our group with a raised plasma creatinine level did not improve the correlation. It is likely that a series of measurements are needed to assess longterm control accurately when testing for associations with diabetic complications.

The severity of retinopathy was related to the duration of diabetes, whereas the degree of autonomic dysfunction was not. Obviously in insulin independent diabetics the known duration is likely to be inaccurate, but analysing the data for insulin dependent diabetics alone did not affect these correlations. As many have shown, disease duration affects the incidence of complications but in this study we were testing for correlations with their severity.

The standard deviation and deep breathing tests are both measurements of sinus arrhythmia. This has been shown to be mediated entirely by vagal parasympathetic effects on the heart [10]. The finding that abnormalities in both tests were strongly correlated thus suggests that both are indicating the effects of vagal neuropathy. The deep breathing test was the more sensitive of the two, but the standard deviation test is a useful standby in patients in whom a good respiratory effort is unobtainable. The Valsalva ratio, which is influenced by both sympathetic and parasympathetic activity [11], was often found to be low in association with reduced sinus arrhythmia. However, the variability in response to this manoeuvre in normal subjects [4] resulted in only four retinopathy patients having ratios below the lower limit of normal. 
Sixteen patients had a resting tachycardia which accords with other reports that diabetics commonly have high resting heart rates $[2,12,13]$. In our patients this tachycardia was not associated with abnormalities in the deep breathing test, the Valsalva ratio, nor with the degree of retinopathy. A resting tachycardia is therefore an unreliable marker of cardiac autonomic neuropathy.

Acknowledgements. We are grateful to the staff of St. Thomas' Hospital Eye Department for their cooperation and to Miss F. Shenouda for performing the $\mathrm{HbA}_{1}$ assays.

\section{References}

1. Pirart J (1977) Diabète et complications dégéneratives présentation d'une étude prospective portant sur 4400 cas observés entre 1947 et 1973. Diabete Metab 3:97-107

2. Clarke BF, Ewing DJ, Campbell IW (1979) Diabetic autonomic neuropathy. Diabetologia 17: 195-212

3. Mackay JD, Page MMcB, Cambridge J, Watkins PJ (1980) Diabetic autonomic neuropathy. The diagnostic value of heart rate monitoring. Diabetologia 18:471-478

4. Smith SE, Smith SA (1981) Heart rate monitoring in healthy subjects measured with a bedside computer-based technique. Clin Sci (in press)

5. Ewing DJ, Campbell IV, Burt AA, Clarke BF (1973) Vascular reflexes in diabetic autonomic neuropathy. Lancet 2: 1354-1356

6. Snedecor GW, Cochran WG (1967) Statistical Methods. The Iowa State University Press, Ames, Iowa, USA, pp 155-157 and 391-393

7. Donovan RJ (1978) Prevalence of retinopathy in a diabetic clinic. Br Med J 1: 1441-1442

8. Baron MD, Shenouda FS, Sönksen PH (1980) Micro-column method for $\mathrm{HbA}_{1}$ determination. Lancet 1 : 1114-1116

9. Dandona P, Freedman D, Moorhead JF (1979) Glycosylated haemoglobin in chronic renal failure. Br Med J 1 : 1183-1184

10. Wheeler T, Watkins PJ (1973) Cardiac denervation in diabetes. Br Med J 4: 584-586

11. Bennett T, Farquhar IK, Hosking DJ, Hampton JR (1978) Assessment of methods for estimating autonomic nervous control of the heart in patients with diabetes mellitus. Diabetes 27 : $1167-1174$

12. Murray A, Ewing DJ, Campbell IW, Neilson JMM, Clatke BF (1975) R-R interval variations in young male diabetics. Br Heart J 37: 882-885

13. Ewing DJ, Campbell IW, Clarke BF (1981) Heart rate changes in diabetes mellitus. Lancet 1: 183-186

Received: 18 March 1981

and in revised form: 30 July 1981

Professor S. E. Smith

Department of Pharmacology

St. Thomas's Hospital Medical School

London SE1 7EH, UK 